\title{
Acute Toxicity and Oral Glucose Tolerance Test of Ethanol and Methanol Extracts of Antihyperglycaemic Plant Cassia Alata Linn
}

\author{
${ }^{1}$ L. Priyadarshini, ${ }^{2}$ P.B.Mazumder and ${ }^{3}$ M.D. Choudhury. \\ ${ }^{1,2}$, Department of Biotechnology, Assam University Silchar, Assam, India. \\ ${ }^{3}$ Department of life science, Assam University Silchar, Assam, India.
}

\begin{abstract}
The present study was carried out to check the toxicity and glucose tolerance activity of ethanol and methanol extract of Cassia alata Linn using swiss albino mice. Mice appeared to be normal and no mortality was observed in the acute toxicity test after treated with an extract up to a concentration of $3000 \mathrm{mg} / \mathrm{kg}$ body weight. It ensures that the plant as safe for use as a medicinal plant. The glucose utilization (OGTT) was evaluated using STZ induced diabetic mice. The study provides remarkable evidence about the ability of the extracts in reducing blood glucose level. The \%glycaemic change of ethanol and methanol extract is 18.74 and 8.35 respectively after 180min of glucose load, which is lesser than the DC (diabetic control) which showed a $\%$ glycaemic change of 132.94. The result in the present study endicates that the plant Cassia alata Linn. might represent a good candidate for further investigation as antihyperglycaemic plant.
\end{abstract}

Keywords: Cassia alata Linn.. OGTT, toxicity, STZ, antihyperglycaemic.

\section{Introduction}

Cassia alata Linn. belonging to the subfamily caesalpiniaceae is often called the Ringworm Bush because of its very effective fungicidal properties, for treating ringworm and other fungal infections of the skin. Besides antifungal activity it is known to have laxative properties [1], antihyperglycemic activity [2], hepatoprotective [3], anti-infective activity, etc. Among which anti-hyperglycemic activity is worth studying.

Toxicity is the fundamental science of poison. The Organization for Economic and Development (OECD) mentioned acute toxicity as the advance effect occurring within a short time of oral administration. It includes observational data gathering and data utilization to predict outcome of exposure in human and animals. The ancient humans categorized some plants as harmful and some as safe [4]. Medicinal plants must be ensured to be safe before they could be used as medicines. The key step in ensuring the safety of drugs is to examine the toxicity of the plant using appropriate animal models, and acute toxicity test is just one of a set of toxicity tests that are used. Glucose tolerance test is a clinical practice and research to identify impaired glucose tolerance. It is a standard procedure that addresses how quickly exogenous glucose can be cleared from blood. Impairment of glucose tolerance i.e, longer time to clear given amount of glucose, indicates problems with maintenance of glucose homeostasis.

This study aims to determine the toxic effect of the plant in-order to ascertain its safety uses. Hence the ethanol extract, methanol extract and aqueous extract of Cassia alata Linn. were analyzed for their acute toxicity profile with reference to behavioral aspects, in Swiss Albino mice.

\section{Materials and Method}

2.1 Plant collection and extract preparation: Cassia alata Linn. is an easily accessible plant and was collected from Imphal west, Manipur. The plant leaves were washed thoroughly to free from debris and were shade dried. The dried plant leaves were sliced, ground coarsely and stored for further use. The shade dried coarsely powdered leaves were subjected to continuous hot extraction (soxhlet) using the following solvents successively- Petroleum ether, acetone, ethyl acetate, ethanol, methanol and aqueous. This process is continuous and is carried out until solvent in the tube becomes colorless. The advantage of the method is that large amounts of plant extract can be extracted with a much smaller quantity of solvent.

2.2 Test animals: For this assay, Swiss albino mice weighing 20-30g obtained at $8 \mathrm{wk}$ of age from Pasteur institute Shillong, Meghalaya and were allowed to acclimatize to their surroundings for $2 \mathrm{wk}$. artificial light was maintain 12:12 hr light dark cycle. The temperature of the room was kept constant at $24^{\circ} \mathrm{C}$. At $10 \mathrm{wk}$ of age, mice were divided into groups required for the experiments. Ethics approval was obtained from the ethics committee Assam University, and all experiments were in accordance with the guidelines for the care and use of laboratory animals specified by this committee.

2.3 Toxicity test: Acute oral toxicity test was performed as per Organization for Economic Co-operation and Development (OECD) guidelines 423 [5]. The test was performed using healthy young adult female Swiss 
albino mice, nulliparous, non-pregnant and weighing 22-30g. The animals were divided into 9 groups containing 3 mice, the first three for ethanol extract treatment; second three for methanol extract treatment and the last three as control. The test substance was administered in a single dose by gavage using specially designed mice oral needle following a period of 5hrs fasting, animals were weighed and the test substance was administered orally at a dose of $1000,2000,3000 \mathrm{mg} / \mathrm{kg}$ body weight. The control group was administered gum acacia the solvent. The volume of the test substance administered was $1 \mathrm{ml} / \mathrm{kg}$ body weight. The animals were observed individually after dosing with special attention given during the first 4 hours and daily thereafter, for a period of 14 days.

2.4 Oral Glucose tolerance test: All the mice were divided into 5 groups, each group containing 3 mice. The divided groups are NC (normal control), DC (diabetic control), DS (diabetic mice receiving glabenclamide), ETDM (ethanol extract treated diabetic mice) and MTDM (methanol extract treated diabetic mice). Diabetes was induced to all groups except NC by intra-peritoneal injection (IP) of STZ (50 mg STZ/kg body weight for five consecutive days). The blood glucose levels were measured from tail-vein blood of all groups by glucometer. Mice with blood glucose level above $200 \mathrm{mg} / \mathrm{dl}$ were considered as diabetic and were recorded as 0 min. Without delay, glucose solution ( $2 \mathrm{gm} / \mathrm{kg}$ body weight) was administered to all groups by gastric tube orally. At the same time $100 \mathrm{mg} / \mathrm{kg}$ body weight each of standard drug glabenclamide, ethanol extract and methanol extract were administered orally to respective groups. The blood glucose level was measured after 30 mins, 90 mins and 180 mins. [6].

Blood samples were collected from the vein of the mice and the blood glucose level was tested with glucometer according to the manufacturer's protocol. The glucose level was expressed in percentage (\%) change from the initial glycaemia using the following formula: $\%$ glycaemia change $=(\mathrm{Gx}-\mathrm{Go}) /$ Go $\mathrm{X} 100$

Go is the glycaemia value at time zero after overnight fasting; $G x$ is the glycaemia value at $\mathrm{x}$ minutes after vehicle or extract administration.

\section{Results}

3.1 Acute toxicity study of ethanol extract and methanol extract of Cassia alata linn.

The present study conducted as per the OECD guidelines 423 revealed that ethanol and methanol extracts of Cassia alata Linn did not produce any mortality throughout the study period of 14 days even when the limit dose was maintained at $3000 \mathrm{mg} / \mathrm{kg}$ body weight. There was no sign of tremors, convulsions, salivation, diarrhea, lethargy, sudden or drastic change of body weight and coma. And also there were no changes in eyes, respiratory circulation, sleep, etc. The oral LD50 was indeterminable being concentration in excess of $3000 \mathrm{mg} / \mathrm{kg}$ body weight. Hence, testing the extracts at a higher dose may not be necessary and the extracts were practically non-toxic.

TABLE 1: Effect of administering different doses of Cassia alata Linn ethanol extract and methanol extract on body weight of mice over a period of two weeks:

Table 1.1

\begin{tabular}{|l|l|l|l|l|}
\hline S1. No. & Treatment days & \multicolumn{4}{|l|}{ Extract $1000 \mathrm{mg} / \mathrm{kg}$ body weight } \\
\cline { 3 - 5 } & & M.E & E.E & G.A.(control) \\
\hline 1 & 0 & $23.71 \pm 0.50$ & $24.66 \pm 0.90$ & $24.05 \pm 0.85$ \\
\hline 2 & 2 & $23.75 \pm 0.65$ & $27.21 \pm 1.31$ & $24.03 \pm 0.82$ \\
\hline 3 & 4 & $23.92 \pm 0.83$ & $27.85 \pm 1.09$ & $24.34 \pm 0.62$ \\
\hline 4 & 6 & $24.04 \pm 0.75$ & $27.85 \pm 1.10$ & $24.60 \pm 0.63$ \\
\hline 5 & 8 & $24.36 \pm 0.58$ & $28.34 \pm 0.79$ & $24.84 \pm 0.62$ \\
\hline 6 & 10 & $24.42 \pm 0.95$ & $28.39 \pm 0.73$ & $25.19 \pm 0.53$ \\
\hline 7 & 12 & $24.71 \pm 1.09$ & $28.81 \pm 0.35$ & $25.47 \pm 0.52$ \\
\hline 8 & 14 & $25.40 \pm 1.49$ & $30.14 \pm 0.27$ & $25.62 \pm 0.55$ \\
\hline
\end{tabular}

Table 1.2

\begin{tabular}{|l|l|l|l|l|}
\hline Sl. No. & Treatment days & \multicolumn{2}{l|}{ Extract $2000 \mathrm{mg} / \mathrm{kg}$ body weight } \\
\cline { 3 - 5 } & & M.E & E.E & G.A.(control) \\
\hline 1 & 0 & $22.61 \pm 0.24$ & $23.62 \pm 1.36$ & $23.53 \pm 0.37$ \\
\hline 2 & 2 & $22.94 \pm 0.2$ & $25.77 \pm 1.64$ & $23.72 \pm 0.34$ \\
\hline 3 & 4 & $23.06 \pm 0.24$ & $26.97 \pm 1.90$ & $23.92 \pm 0.18$ \\
\hline 4 & 6 & $23.17 \pm 0.16$ & $27.08 \pm 1.86$ & $24.18 \pm 0.27$ \\
\hline 5 & 8 & $23.17 \pm 0.28$ & $28.08 \pm 2.21$ & $24.31 \pm 0.39$ \\
\hline 6 & 10 & $23.29 \pm 0.15$ & $28.30 \pm 2.05$ & $24.55 \pm 0.29$ \\
\hline 7 & 12 & $23.31 \pm 0.18$ & $28.97 \pm 2.08$ & $24.79 \pm 0.17$ \\
\hline 8 & 14 & $23.59 \pm 0.38$ & $29.52 \pm 2.11$ & $24.85 \pm 0.55$ \\
\hline
\end{tabular}


Table 1.3

\begin{tabular}{|l|l|l|l|l|}
\hline \multirow{2}{*}{$\begin{array}{l}\text { Sl. } \\
\text { No. }\end{array}$} & \multirow{2}{*}{$\begin{array}{l}\text { Treatment } \\
\text { days }\end{array}$} & \multicolumn{4}{|l|}{ extracts3000 $\mathrm{mg} / \mathrm{kg}$ body weight } \\
\cline { 3 - 5 } & M.E & E.E & G.A(control) \\
\hline 1 & 0 & $23.77 \pm 0.88$ & $23.47 \pm 1.06$ & $24.00 \pm 0.51$ \\
\hline 2 & 2 & $23.93 \pm 0.82$ & $24.84 \pm 1.27$ & $24.12 \pm 0.47$ \\
\hline 3 & 4 & $23.99 \pm 0.70$ & $24.96 \pm 1.90$ & $24.44 \pm 0.40$ \\
\hline 4 & 6 & $24.45 \pm 0.70$ & $25.10 \pm 1.54$ & $24.54 \pm 0.40$ \\
\hline 5 & 8 & $24.46 \pm 0.76$ & $25.29 \pm 2.60$ & $24.66 \pm 0.44$ \\
\hline 6 & 10 & $24.58 \pm 0.98$ & $25.56 \pm 2.60$ & $24.77 \pm 0.49$ \\
\hline 7 & 12 & $24.66 \pm 1.29$ & $26.11 \pm 2.55$ & $24.92 \pm 0.60$ \\
\hline 8 & 14 & $24.73 \pm 1.33$ & $26.31 \pm 2.63$ & $25.09 \pm 0.49$ \\
\hline
\end{tabular}

Values are mean $\pm S$ D of three observations where M.E=methanol extract, E.E=ethanol extract and G.A=gum $\operatorname{acacia}(2 \%)$.

Table 2: percentage change in body weight of mice after 14 days of treatment.

\begin{tabular}{|l|l|l|l|l|}
\hline Sl.no & $\begin{array}{l}\text { Concentration } \\
(\mathrm{mg} / \mathrm{kg} \text { b.wt. }\end{array}$ & $\begin{array}{l}\text { \% change in b.wt. of } \\
\text { mice treated with M.E }\end{array}$ & $\begin{array}{l}\% \text { change in b.wt. of } \\
\text { mice treated with E.E }\end{array}$ & $\begin{array}{l}\% \text { change in b.wt. of } \\
\text { mice } \\
\text { Control }\end{array}$ \\
\hline 1 & 1000 & 7.13 & 22.22 & 6.53 \\
\hline 2 & 2000 & 4.34 & 30.56 & 5.61 \\
\hline 3 & 3000 & 4.04 & 12.10 & 4.54 \\
\hline
\end{tabular}

M.E=methanol extract, E.E=ethanol extract, b.wt=body weight.

Fig. 1: \% change in body weight of the mice after 14 days of treatment with M.E and E.E.

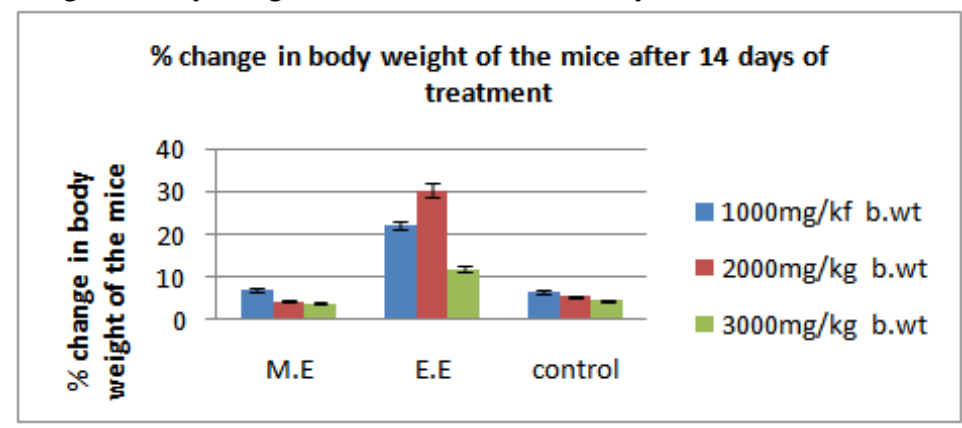

EE, Ethanol Extract; ME, Methanol Extract.

3.2 Glucose tolerance effect of ethanol and methanol extracts: After oral administration of glucose to all the 5 groups of mice, blood glucose levels were significantly higher and reached a peak blood glucose level at a certain period of time in each group. The recorded blood glucose levels and \% glycaemia change for every $30 \mathrm{~min}$, 60min, $90 \mathrm{~min}$, and $180 \mathrm{~min}$ of each group are shown in table 3 . In diabetic control mice the peak blood glucose level was observed after $90 \mathrm{~min}$ and it remained above normal even after 2 hours of glucose administration. Mice treated with standard drug glabenclamide, ethanol extract and methanol extract showed a significant decrease in blood glucose level at $180 \mathrm{~min}$ as compared with diabetic control mice. Both ethanol and methanol extracts caused a significant raise of blood glucose at 30 minute time point of the test. After that, the blood glucose level of all extracts treated mice steadily revert back to initial glucose level. Methanol Extract reduced more blood sugar level in diabetic mice compared to ethanol extract treated and control diabetic mice (Figure 2).

Table 3: effect of ethanol extract and methanol extract on glucose metabolism in NC, DC, DS, EETDM and Metdm.

\begin{tabular}{|l|l|l|l|l|}
\hline \multirow{2}{*}{ mice groups } & \multicolumn{4}{|l|}{ \%glycaemia change. (Gx -Go )/ G X100 } \\
\cline { 2 - 5 } & After 30 min & After 60 min & After 90 min & After 180 min \\
\hline NC & 48.64 & 43.42 & 38.59 & 27.05 \\
\hline DC & 70.67 & 105.04 & 141.94 & 132.94 \\
\hline DS & 9.8 & 2.86 & -3.8 & -11.18 \\
\hline EETDM & 40.21 & 25.55 & 21.50 & 18.74 \\
\hline METDM & 24.16 & 18.01 & 15.83 & 8.35 \\
\hline
\end{tabular}


NC, Normal control; DC, Diabetic Control; DS, Diabetic Standard; EETDM, Ethanol Treated Diabetic Mice; METDM, Methanol Extract Treated Diabetic Mice;

Figure 2: Graph showing effect of ethanol extract and methanol extract on glucose metabolism in NC, DC, DS, EETDM and METDM.

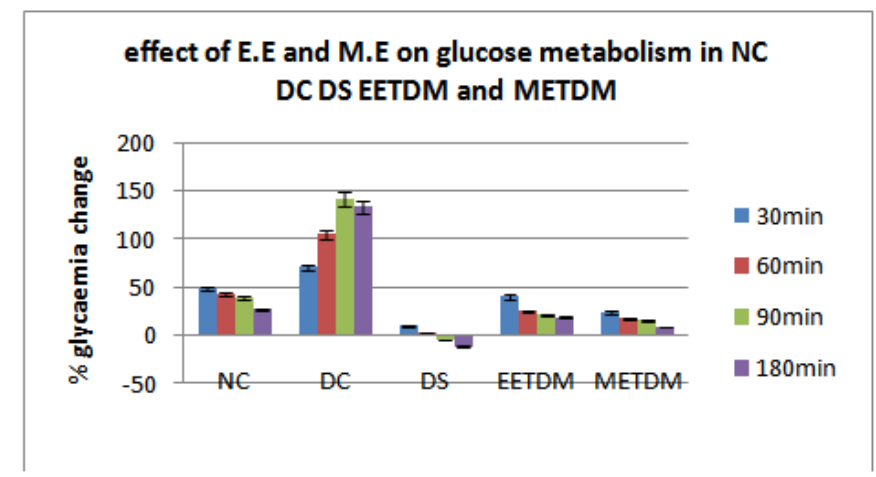

NC, Normal control; DC, Diabetic Control; DS, Diabetic Standard; EETD, Ethanol Treated Diabetic Mice; METD, Methanol Extract Treated Diabetic Mice.

\section{Discussion}

In the acute toxicity test of the aqueous extract of Cassia alata Linn, there was no mortality or any signs of behavioral changes or toxicity observed after oral administration of extract up to the dose level of $3000 \mathrm{mg} / \mathrm{kg}$ body weight in mice. This finding supports the study which presents the strong evidence of the nontoxic effect of the ethanolic extract of the said plant [7].This finding was against the study which reported that the LD50 of ethanol extract as $895 \mathrm{mg}$ [7]. Oral glucose tolerance test (OGTT) measures the body's ability to use glucose, the body's main source of energy [8]. Cassia alata Linn. are used as antidiabetic plant in traditional medicines. In our study, it was observed that the ethanol and methanol extracts of the said plant enhanced glucose utilization. The said extracts were able to reduce blood glucose level on STZ induced diabetic mice. According to our study the methanol extract showed more blood glucose reducing ability with a \%glycemic change of 8.35 than the ethanol extract which gave \% glycaemic change of 18.74 . The $\%$ glycaemic change of diabetic mice treated with both the extracts promotes glucose utilization even more than the normal mice (27.05 $\%$ glycaemic change).

\section{Conclusion}

The non-toxic nature of the ethanol extract and methanol extract of Cassia alata Linn. is evident from the acute oral toxicity conducted as per OECD guidelines. The absence of abnormal behavior of the test animals during a period of 14 days suggests the non-toxic nature of the foresaid extracts. Hence Cassia alata Linn. is safe as medicinal plant but further studies are warranted for determining chronic toxic symptoms. Since the glucose utilization in glucose loaded diabetic mice treated with ethanol and methanol extract is significantly enhanced, it can be concluded that the above said extract is having antihyperglycaemic activity. This may be due to the presence of compounds responsible for antihyperglycemic activity for which further investigation is needed.

\section{Reference}

[1]. Elujoba AA, Ajulo OO, and Iweibo, Chemical and biological analysis of Nigerian Cassia species for laxative activity, J pharm biomed anal, 7(12), 1989, 1453-7.

[2]. Palanichamy S, Nagarajan S, and Devasagayam M. Effect of cassia alata leaf extract on hyperglycemic rats, J Ethnopharmacol, 22(7), 1988, 81-90.

[3]. Wegwu, MO, Ayalgu, EO, and Sule, O, Antioxidant protective effects of Cassia alata in rats exposed to carbon tetrachloride, J Appl Environ Mgt., 9(3), 2005, 77-80.

[4]. Pingale SS, Acute toxicity studies for Centella asiatica whole plant powder, Pharmacologyonline, 3, $2008,80-84$.

[5]. OECD Guidelines for the Testing of Chemicals (No. 423), Acute Oral Toxicity-Acute Toxic Class Method (Adopted on 17 December 2011).

[6]. Hossain MS, Asadujjaman M, Khan MRI, Ahmed M, and Islam A, Antidiabetic and glycogenesis effects of different fractions of methanolic extract of Momordica charantia (Linn.) in alloxan induced diabetic rats, International Journal of Pharmaceutical Sciences and Research, 2(2), 2011, 404-412.

[7]. Pieme, C.A., V.N. penlap, b. nkegoum, C.L. Teziebou, F.X. Etoa and Ngongang, 2006. Evaluation of acute and subacute activities of aqueous ethanolic extract of Senna alata (L). roxb (caesalpiniaceae). Afr. J. biotechnology, 2006, 5, 283-289.

[8]. Timothy SY, lamu FW, Rhoda AS, Adati RG, Maspalma ID, Askira AM, Acute toxicity, phytochemistry and antibacterial activity of aqueous and ethanolic leaf extracts of Cassia alata Linn., International research journal of pharmacy, 3(6), 2012.

[9]. Du-Vigneaud V, and Karr WG, Carbohydrate utilization, rate of disappearance of D-glucose from the blood, J. Biological Chem., 66, 1925, 281-300. 